\title{
Concomitant replacement of the ascending aorta is free-for some
}

\author{
Nicholas D. Andersen, MD, and G. Chad Hughes, MD
}

\footnotetext{
From the Division of Cardiovascular and Thoracic Surgery, Department of Surgery, Duke University Medical Center, Durham, NC.

Disclosures: Authors have nothing to disclose with regard to commercial support.

Received for publication June 13, 2016; accepted for publication June 16, 2016; available ahead of print July 16, 2016.

Address for reprints: Nicholas D. Andersen, MD, Division of Cardiovascular and Thoracic Surgery, Duke University Medical Center, Box 3443, Durham, NC 27710 (E-mail: Nicholas.andersen@duke.edu).

J Thorac Cardiovasc Surg 2016;152:799-800

$0022-5223 / \$ 36.00$

Copyright (C) 2016 by The American Association for Thoracic Surgery

http://dx.doi.org/10.1016/j.jtcvs.2016.06.022
}

Prophylactic replacement of the ascending aorta is warranted when the risk of death from dissection or rupture exceeds the risk of surgical repair. Calculating these risks is an imperfect science, however, and risk estimates differ according to several patient, surgeon, and institutional variables. In their small, single-institution, single-surgeon study in the current issue of the Journal, Peterss and colleagues ${ }^{1}$ from Yale have attempted to determine the added incremental risk of concomitant supracoronary ascending aorta replacement with aortic valve replacement (AVR; Wheat procedure ${ }^{2}$; Figure 1) relative to patients undergoing AVR alone. Patients were selected for concomitant ascending aorta replacement on the basis of a size threshold of $4.5 \mathrm{~cm}$, and approximately $70 \%$ of patients had bicuspid aortic valves. Peterss and colleagues ${ }^{1}$ then compared 2 techniques for ascending aorta replacement, either a clamped distal anastomosis or an open distal anastomosis (hemiarch) with femoral artery cannulation and straight circulatory

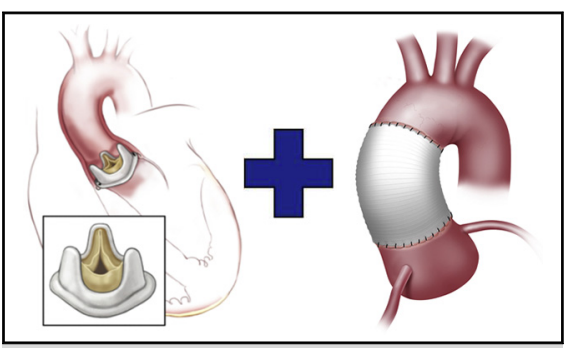

Wheat procedure: Replacement of the aortic valve and supracoronary ascending aorta.

\section{Central Message}

Concomitant ascending aorta replacement can be performed with trivial incremental risk in elective low-risk patients when operations are performed by a high-volume aortic subspecialist.

See Article page 791.

arrest without adjunctive cerebral perfusion. By means of a propensity matching approach, Peterss and colleagues ${ }^{1}$ found that there was essentially no added surgical morbidity or mortality with the addition of ascending aorta replacement to isolated AVR and that the perioperative mortality was $0 \%$ regardless of treatment group. These data suggest
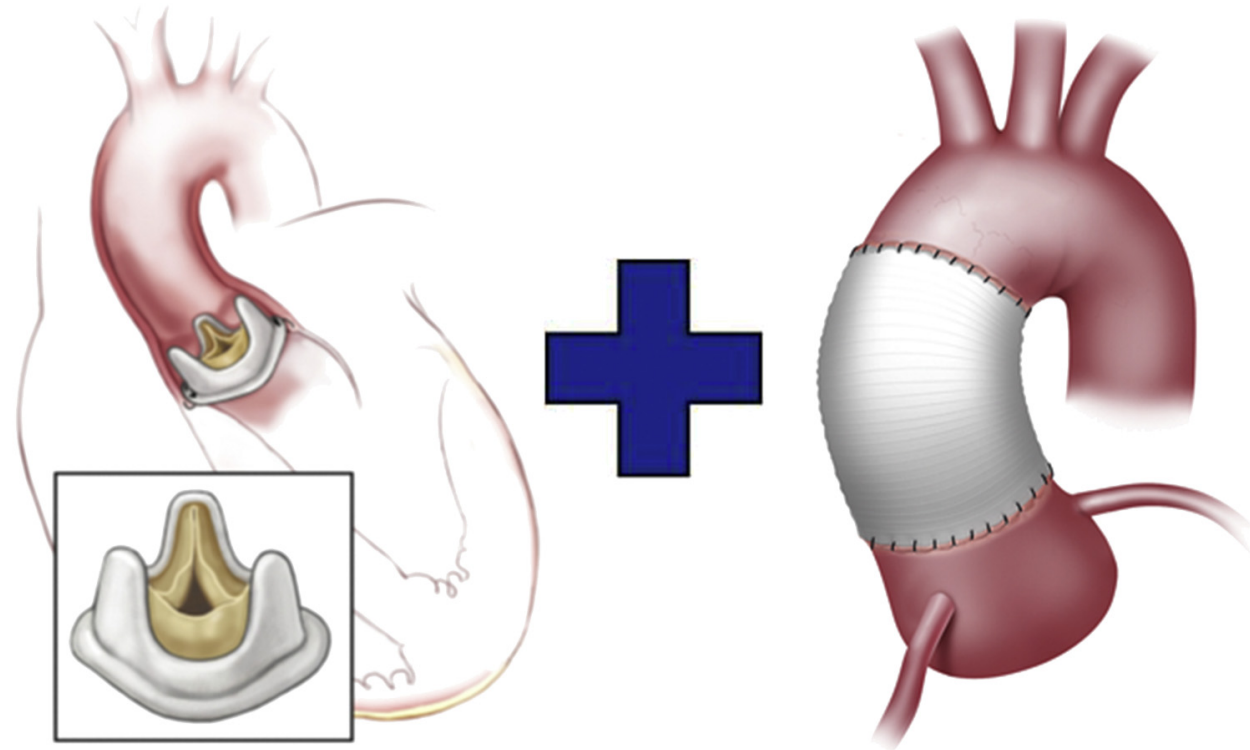

FIGURE 1. Wheat procedure: Replacement of the aortic valve and supracoronary ascending aorta. 
that the incremental risk of concomitant ascending aorta replacement with AVR is infinitesimally small, and thus the threshold for concomitant ascending aorta replacement should be infinitesimally low. Peterss and colleagues ${ }^{1}$ concluded that concomitant ascending aorta replacement with or without an open distal anastomosis should be performed "without any hesitation" in patients with small aneurysms at experienced centers.

These results need to be interpreted in the context of the study limitations, of which there are several. First, all operations were performed by a single high-volume aortic surgeon at an experienced aortic center. It has become clear during the last decade that outcomes of thoracic aortic operations are heavily influenced by surgeon experience, and therefore the results reported here are likely not generalizable at the national level. ${ }^{3}$ Second, the patient population consisted primarily of patients with bicuspid valves who were at low risk, with predicted mortality scores lower than $1 \%$. Caution should therefore be taken in extrapolating these data outside the young, elective, low-risk patient cohort. Finally, the study is small and woefully underpowered $(<100$ patients per treatment group) to detect the mortality differences it intends to identify. A back-of-the-envelope power calculation reveals that a study would require approximately 900 patients in each treatment arm to detect with $80 \%$ probability a mortality difference between $1 \%$ and $3 \%$, which represent the approximate mortalities of elective AVR and elective ascending aorta replacement reported at the national level. ${ }^{4}$ Determining differences in freedom from late aortic events is similarly impossible to document without a larger sample size, given that late aortic events occur after AVR in fewer than $1 \%$ of patients with bicuspid aortic valves. ${ }^{5}$ The study by Peterss and colleagues ${ }^{1}$ is thus unable to provide meaningful comparative data between treatment arms and serves primarily to document the excellent surgical outcomes achieved at this center.

In short, this study from Peterss and colleagues ${ }^{1}$ demonstrates that concomitant replacement of the ascending aorta at the time of AVR is free-at least for some surgeons, patients, and centers. These results should be extrapolated to other arenas of care with caution, however, and are insufficient to inform national recommendations for prophylactic ascending aorta replacement. A larger population-level data set is required to better define the risk of concomitant ascending aorta replacement at the time of AVR.

\section{References}

1. Peterss S, Charilaou P, Dumfarth J, Yupeng L, Bhandari R, Tranquilli M, et al. Aortic valve disease with ascending aortic aneurysm: impact of concomitant root-sparing (supracoronary) aortic replacement in nonsyndromic patients. $J$ Thorac Cardiovasc Surg. 2016;152:791-8.

2. Wheat MW Jr, Wilson JR, Bartley TD. Successful replacement of the entire ascending aorta and aortic valve. JAMA. 1964;188:717-9.

3. Miller DC. Another meiosis in the specialty of cardiovascular and thoracic surgery: birth of the purebred "thoracic aortic surgeon" J Am Coll Cardiol. 2014; 63:1804-6.

4. Williams JB, Peterson ED, Zhao Y, O'Brien SM, Andersen ND, Miller DC, et al. Contemporary results for proximal aortic replacement in North America. J Am Coll Cardiol. 2012;60:1156-62.

5. Itagaki S, Chikwe JP, Chiang YP, Egorova NN, Adams DH. Long-term risk for aortic complications after aortic valve replacement in patients with bicuspid aortic valve versus Marfan syndrome. J Am Coll Cardiol. 2015;65:2363-9. 